\title{
Imagining Acupuncture: Images and the Early Westernization of Asian Medical Expertise
}

\author{
Roberta Bivins \\ Centre for the History of Medicine \\ University of Warwick
}

\begin{abstract}
While an increasing number of studies have now examined the textual transmission of medical knowledge from one culture to another, less work has been done on the role and impact of medical images and image-making in knowledge transmission and reception. Here, drawing on the example of acupuncture, I assess the 'translation' of images, their adaptation in response to the visual norms and medical politics of the receiving culture, and their enduring effects on early responses to Chinese medical expertise and practices in Europe.
\end{abstract}

\section{Keywords}

images in medicine, transmission, cross-cultural, acupuncture, Ten Rhijne, Kaempfer, medical technology

Chinese medicine draws upon a rich iconographic tradition; through this tradition (as well as careful observation, and the translation of medical texts), European medical practitioners and patients first became aware of the medical expertise of Asia. As a therapeutic modality defined by and practised in conjunction with a unique set of body maps, acupuncture's Western history in particular can be traced in the images through which it was represented. From Wilhelm Ten Rhijne's 1683 Mantissa Schematica: De Acupunctura to contemporary medical textbooks, changes in the European visual culture of acupuncture record different attempts to incorporate the technique into Western theory and practice — and expose, too, areas of cultural, medical, and scientific intransigence. Thus such images offer us primary evidence of the processes by which Chinese medical knowledge and culture has been globalised: how it has been perceived, translated, transmitted, received, and practised in other medical settings and cultures.

What we summarise under the heading of 'transmission' is, of course, a complex and multi-faceted process even within a single culture. As the seventeenth-century French natural philosopher Blaise Pascal recognised, the 
communication of knowledge involves many interactive elements (parsed by scholars of his work as content, medium, receiver, and context). Perhaps more crucially, Pascal noted that successful communication depended not just on the value or truthfulness of the knowledge to be conveyed, but on knowing the tastes, pleasures, and accepted truths of its would-be recipient: 'we must pay attention to the person whom we are addressing: we must know their mind and heart, what principles they grant, what things they like... the art of persuasion consists in pleasing as much as in convincing-humans being, as they are, governed so much more by whim than by reason'. ${ }^{1}$

Rather more recently, Elisabeth Hsu (among others) has explored the complex processes whereby Chinese medical knowledge is transmitted from one generation to another within China. The pathways she isolated-'secret', 'personal', and 'standardised' - operate to a greater or lesser extent in any medical culture. ${ }^{2}$ One or another of these pathways may dominate the transmission process for any particular kind of medical knowledge, but will rarely if ever operate exclusively. For example, while medical education in the West may well be dominated by 'standardised' knowledge transmission, both 'personal' and 'secret' pathways certainly still operate, as illustrated by Julie Anderson and John Pickstone's work on the Charnely artificial hip, and by the persistence of the culture of surgical 'firms'. ${ }^{3}$

As Volker Scheid has demonstrated in relation to contemporary Chinese medicine, the specific content to be transmitted, too, affects the process and pace of transmission. ${ }^{4}$ In the sphere of medicine, three broad genres of knowledge are involved. Medical theory, comprising cosmologies, models of the body, and aetiologies of health and illness, is perhaps most readily transmissible across physical barriers, as it can take an exclusively textual form. ${ }^{5}$ But cultural barriers are another matter. Medical systems, as many scholars have argued, are highly culturally specific — and the availability of another culture's medical texts is no guarantee of their assimilability or persuasiveness. Medical practice,

1 For the intracultural transmission of (expert, scientific) knowledge, see the essays in Kusukawa and Maclean (eds) 2006, which also examine the role of images in stabilising polysemic knowledge. For Pascal, see specifically Scholar 2006, p. 3, where this quotation from Blaise Pascal, De l'esprit géometrique, c.1655, can be found.

2 See Hsu 1999.

3 See Anderson 2006, pp. 175-92; Pickstone 2006, pp. 17-36.

4 Scheid 2002.

5 And even text-to-text transmission can hardly be regarded as a straightforward process, in which meaning in the origin culture and meaning in the destination culture bear a one-to-one relation to each other. See, for example, the studies (focused primarily on the transmission of scientific rather than specifically medical knowledge) in Ragep and Ragep, with Livesey (eds) 1996. Moreover, as Pascal's wry quotation suggests, the movement of knowledge from one location to another does not ensure the successful communication of that knowledge. 
meanwhile, entails methods of diagnosis, prognosis, and treatment; the content and style of the doctor-patient encounter; and the management of illness and health. These are perhaps best transmitted through personal contact and direct experience. And the technologies of medicine-its materia medica, instruments, devices, body maps, diagnostic charts, etc. - may be more or less transportable, but are rarely complete without both textual and experiential glosses. Consider, for example, the stethoscope-or more properly, the use of mediate auscultation (the technique of diagnosing chest conditions through listening indirectly to the sounds of respiration, etc.). Three components had to be transmitted for the practice to be successful and stable. These included the tool itself, the method of using it effectively, and the knowledge required to differentiate between newly audible sounds, and to associate those sounds with specific pathologies. Detailed knowledge of anatomy and personal experience using the technique under the close supervision of an expert proponent-in this case, the stethoscope's inventor, René Laënnec-were vital to its successful adoption, as were accessible and excellent translations of relevant treatises. ${ }^{6}$ Images additionally played a role in the eventual adoption of the stethoscope. In his first treatise on mediate auscultation, Laënnec presented detailed images and a cross-section of his novel (but fairly simple) instrument. These images allowed doctors remote from Paris to experiment with the tool themselves, and to test and assert its utility through direct experience. ${ }^{7}$

\section{Images and acts of transmission}

The study of images is increasingly recognised as essential to understanding the processes whereby expertise diffuses within, or passes from one culture to another. ${ }^{8}$ As the case of stethoscopy demonstrated, images can connect audiences and contexts otherwise separated by time, space, language, or intellectual bent. Even within a broad expert culture, images can operate as more than just illustrations. The philosopher Michael Ruse has offered compelling evidence that pictures - in particular, the portrayal of genetic processes in terms of a topographical landscape-were crucial to the communication of mathematical models of evolutionary genetics to mathematically disinclined

\footnotetext{
${ }^{6}$ See Reiser 1978, and for a more detailed look, Smith 1998. For a slightly different perspective, see Nicholson 1993. On the importance of textual glosses for tools and images, see also Kusukawa and Maclean (eds) 2006.

7 See Smith 1998, pp. 183-216.

${ }^{8}$ For examples, see Gilman 1995, Chapter 1; Kemp 1993, pp. 85-121. For more on the 'visual turn' in history, see Jordanova 2012.
} 
evolutionary biologists, who only then could use them to produce key experiments. ' The use of images can also extend scarce resources and offer up surrogate experiences - as in the case of anatomical dissection and anatomical atlases. ${ }^{10}$ But images do not always play such straightforward roles, and certainly do not reliably speed the transmission process. Images can create unintended meanings. William Hunter, the famous eighteenth-century anatomist noted that while art could present information 'so plain that the unlearned as well as the learned understand it at first sight', it could also be dangerously misrepresentative. ${ }^{11}$ An additional complexity in the iconography of Western medicine and science since the Renaissance is that the images were intentionally directive as well as descriptive. They showed surgeons and artists 'routes' around and through the body, suggested 'appropriate' comparisons and valuations for the observed structures, and so constrained as well as communicated knowledge of the body's inner spaces. ${ }^{12}$ Mark Jenner's recent assessment of English physician Sir John Floyer's early eighteenth- century response to Chinese haptic diagnostics illustrates the operation of such constraints, even in Floyer's very positive response to the images of Chinese 'pulse taking' in Andreas Cleyer's Specimen medicinae Sinicae. ${ }^{13}$ Moreover, images were routinely separated from the texts that glossed them, and re-used, derailing the intended transmission process and sometimes replacing their original meanings with entirely new ones. ${ }^{14}$ As we will see, this has been common in cross-cultural transmission.

\section{Portraying technique, mapping transmission?}

The case of acupuncture neatly exemplifies the difficulties of transmission and their effect on the globalisation of Chinese (or indeed any other) medical culture. Here, I will focus primarily on images created or copied by Westerners, and particularly medical professionals, whether intended for lay or medical audiences. Many of those images, particularly in the first modern wave of acupuncture's transmission to the West (roughly 1670s to 1730s), consisted of maps of the jing-luo and xue-respectively, the dense network of channels

\footnotetext{
9 Ruse 1996, pp. 303-10.

10 See Kemp 1996, esp. pp. 43-59; Kemp 1993; see also Berkowitz 2011, pp. 259-62.

11 Quoted in Kemp 1993, p. 87. For unintended meanings, see also Luthy 2006.

12 Kemp 1993, p. 94, hints at this, as do many primary source accounts. See Schiebinger 1989 for a detailed study of anatomical images and gender in science and medicine.

13 Jenner 2010, pp. 663-7.

14 Kusukawa and Maclean (eds) 2006, pp. 92-6.
} 
through which energy flows around the body; and the specific points at which particular channels and flows could be stimulated by surface interventions, including the insertion of needles or the burning of moxa. Standing between the poles of text and technology, the original maps, charts, and models of a subtle body were certainly tools in Chinese and Japanese medical practice and education. Foreign observers noted these uses. In Japan, interested (if faintly disapproving) Europeans also described the use of these medical images by an enthusiastically self-medicating laity to self-puncture-as one Dutch physician-observer put it, 'the needles are among the portable treasures of the capsule-loving nation'. ${ }^{15}$ This apparent transparency and directness in medical practice was much admired by Westerners more accustomed to the rhetoric and obscurantism - the 'verbal globs of honey' and 'contrived and controversial nonsense' - of élite European physic. ${ }^{16}$ And so they intended to emulate it in transmitting knowledge about acupuncture. One early proponent of the technique remarked: 'Since this method is so very different from the practice of Westerners, and since a thorough demonstration of it would involve a huge amount of labour and since this would not be suited to the flat surface of a book page, I thought it best to present illustrations clarifying separate dissertations. ${ }^{17}$ This physician clearly expected his maps to be attractive and useful to his intended Western audience-European medical professionals. His charts were to be virtual demonstrations, as well as maps for needle placement. He had, after all, seen similar documents working in exactly that way in Japan, as tools and guides of users' hands. But the maps and models also embodied an entirely different medical cosmology, and were imbued with considerable sophisticated medical theory. It was precisely these elements of the images that were obscured or erased when the role of images in Chinese and Japanese medical practice was unquestioningly equated with the purely illustrative and corroborative role that images were coming to have (at least in theory) in Western medicine.

Thus, although often presented by their authors as direct copies of Asian originals, the maps that were actually transmitted to early modern Europe were in fact translations, and as such, were subject to exactly the same kind of errors that have plagued translations of Asian medical texts. Like Chinese medical terminology, the images were variously exoticised, domesticated, over-simplified and embellished. Moreover, in seeking to understand the

${ }^{15}$ Engelbert Kaempfer, 'Acupuncture, A Japanese Cure for Colic', translated in Bowers and Carrubba 1970, p. 304.

16 Ten Rhijne, 'De Acupunctura' and 'Mantissa Schematica', translated in Carrubba and Bowers 1974, p. 375.

17 Translated in Carrubba and Bowers 1974, p. 376. 
process of transmission, it is essential to remember that none of these images existed in a vacuum; they were 'read' in conjunction with an array of material and especially textual sources. Just as the images inflected (and reflected) Western perceptions of acupuncture, so responses to them were enduringly influenced by Western perceptions of China. Similarly, internal debates and trends in Western medicine played a profound role in both the iconography of acupuncture and its reception. ${ }^{18}$

The earliest European medical treatise on acupuncture, Willem ten Rhijne's Dissertatio de Arthritide: Mantissa Schematica: De Acupunctura: Et Orationes Tres..., was based on Ten Rhijne's own observations of medical practice in Japan and his interpretations of rather painfully translated Chinese medical texts. 'I gathered and translated these into Latin', Ten Rhijne confided to his readers, 'with the assistance of Iwanaga Zoko, a Japanese physician who knows Chinese, and with the assistance of Monttongi Sodaio, our interpreter, who speaks faltering Dutch in half words and fragmentary expressions. ${ }^{19}$ Indeed, Ten Rhijne grumbled, his interpreters' 'inexperience and limited vocabulary in Dutch' forced him to 'omit much that was written in Chinese in the original documents. ${ }^{20}$ Just as Ten Rhijne's source texts were, in general, first translated from Chinese into Japanese, from Japanese into Dutch, and finally from Dutch into medical Latin, so too were his images multiply 'translated'-from Chinese originals to Japanese copies (see figure 1) and finally to images modified to suit European iconographic conventions.

In medical publishing, those conventions were rooted in rapidly changing models of the human body drawn from contemporary anatomical studies (see figure 2). Clearly, there is a striking contrast between the Asian and European styles of representing the body. From a Western perspective, the Japanese image shows a body mapped—and by implication, known—primarily on the surface, and with little anatomical detail or specificity. Contemporary Asian images of the internal organs did little to improve Western medical opinion, since they flatly contradicted the anatomical knowledge of the day. Indeed, as an example of the role of selection in the transmission pathway, it is worth noting that Ten Rhijne-medically trained and exhorting emulation, or at least experimentation in a medical audience-did not duplicate these images. His non-medical contemporary, the missionary Andreas Cleyer, did (see figure 3). By contrast, Western images from the same period as the Mantissa Schematica portrayed ever-greater levels of fine detail,

\footnotetext{
${ }^{18}$ For examples of interactions between internal medical debates and responses to acupuncture in the eighteenth and nineteenth centuries, see Bivins 2000, esp. chapters 2 and 3.

19 Translated in Carrubba and Bowers 1974, pp. 377-8.

${ }^{20}$ Ibid.
} 


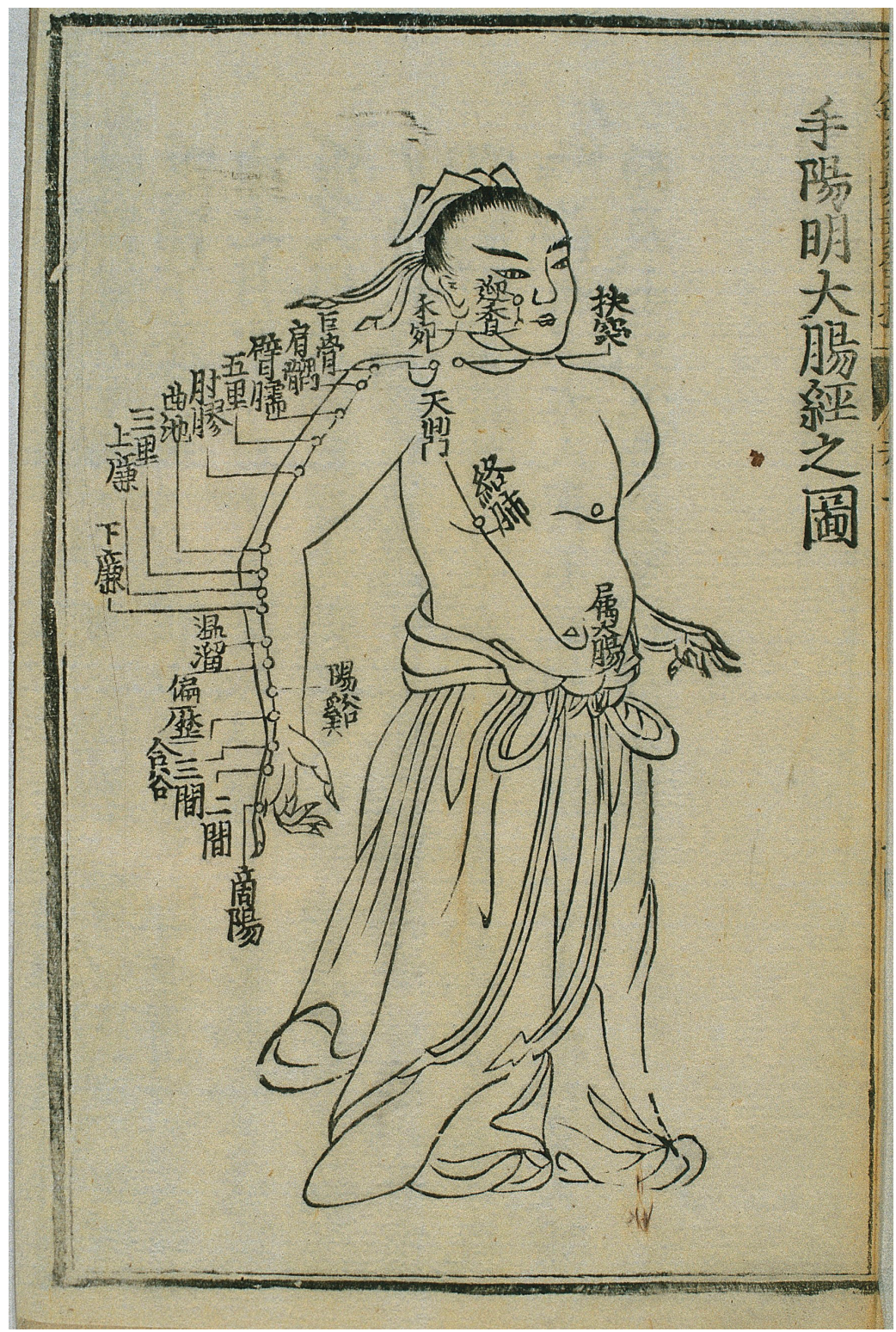

Wellcome Library, London

Fig. 1. The large intestine channel of hand, yangming, from Gao Wu, Zhenjiu jiuying fahui [Explanations of 'Collected Gems of Acupuncture and Moxibustion'], engraved and published in Japan. Library of Zhongguo zhongyi yanjiu yuan (China Academy of Traditional Chinese Medicine). 


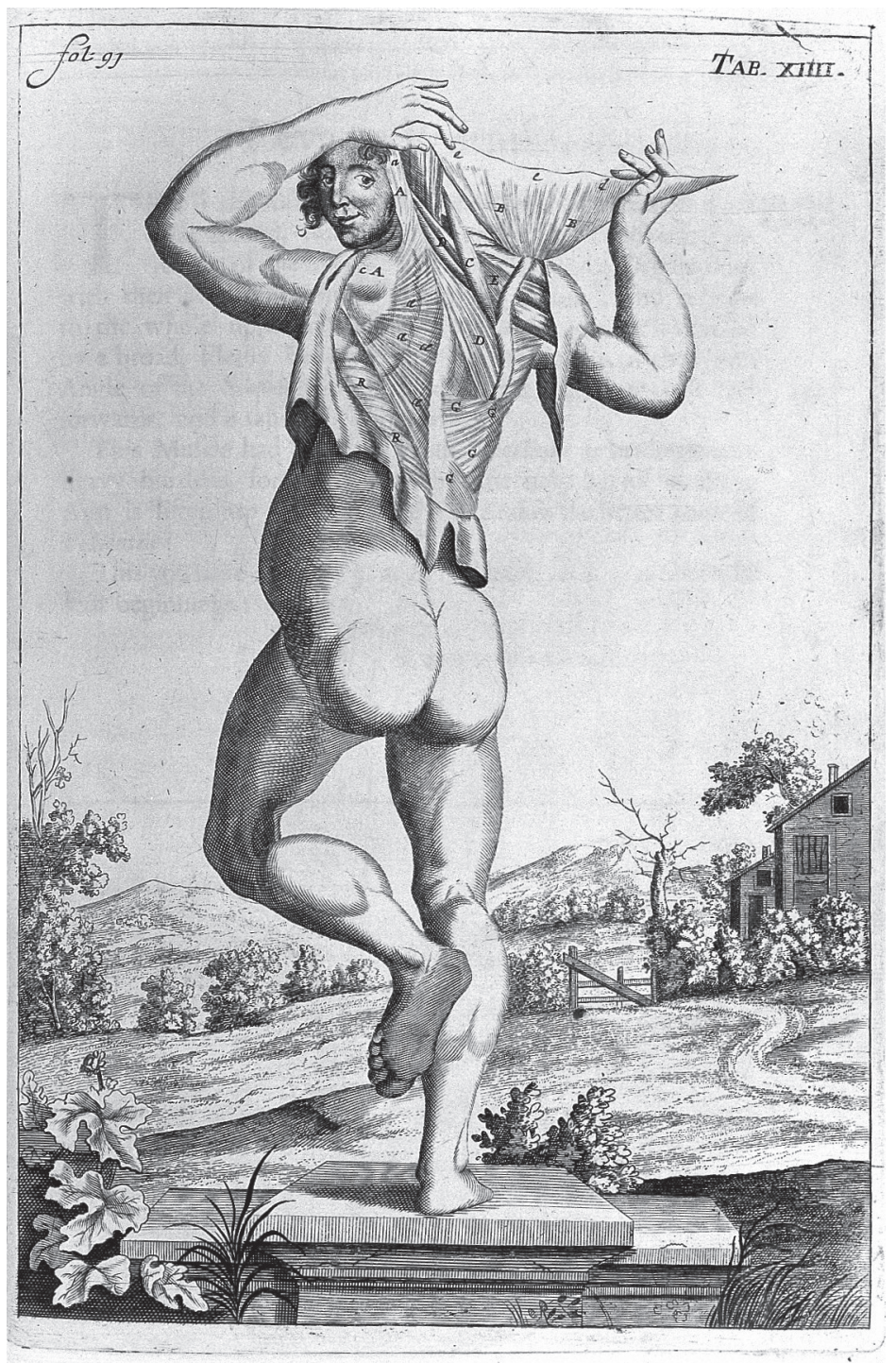

Wellcome Library, London

Fig. 2. Anatomy of the upper back, from John Browne, A compleat Treatise of the Muscles: as they appear in humane body, and arise in dissection . .., London 1681. Note the similarities with Ten Rhyne's 'Chinese' image below, Figure 5. 


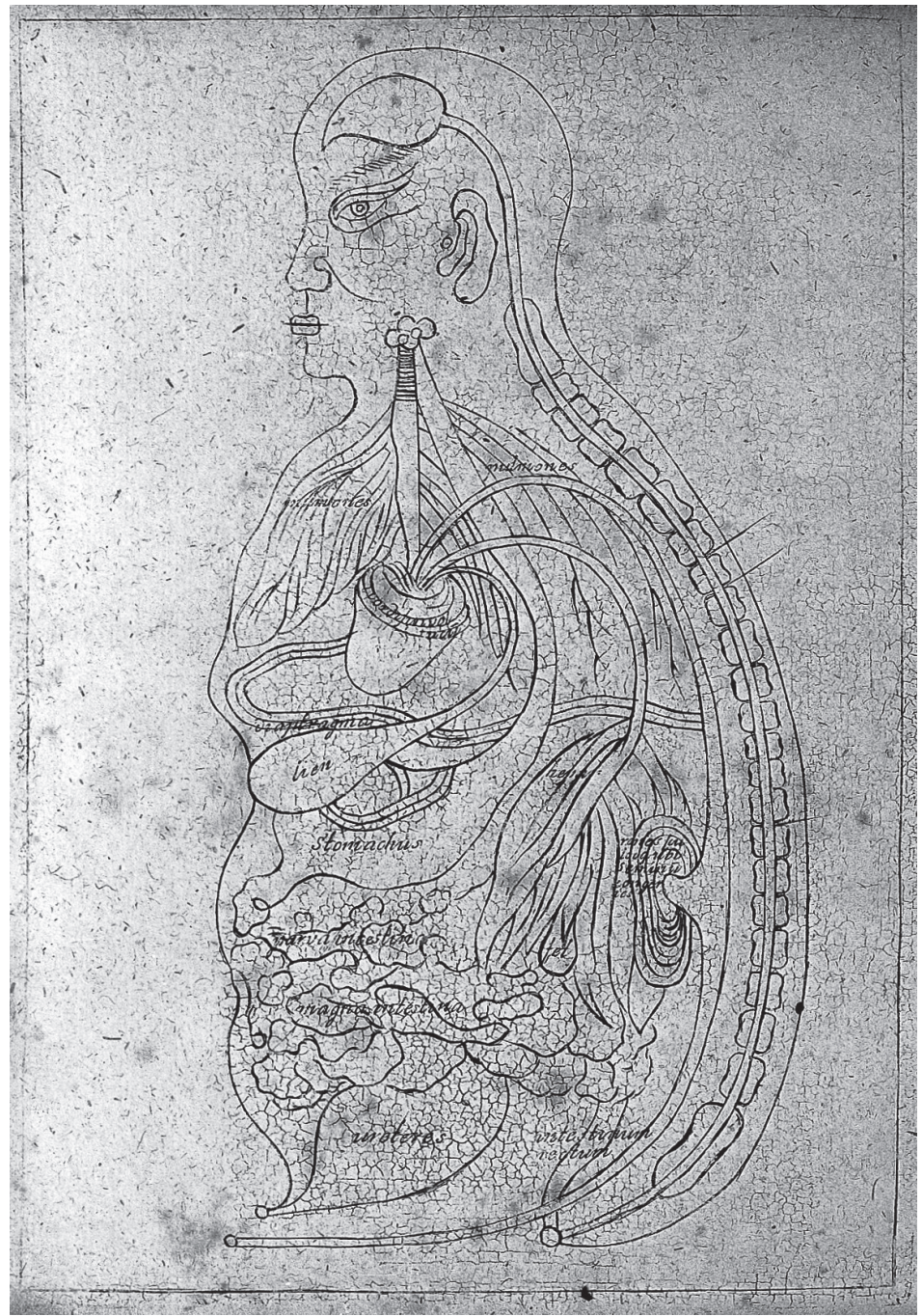

Wellcome Library, London

Fig. 3. 'Anatomical Figure' from Andreas Cleyer, Specimen medicinae Sinicae, sive opuscula medica ad mentem Sinensium, Frankfurt, 1682. 
and ever-deeper explorations beneath the body's surface (see figure 4$) \cdot{ }^{21}$ As a part of the pursuit of naturalism and the culture of 'virtual witnessing', anatomical art conventionally displayed the sheets of flesh which dissection

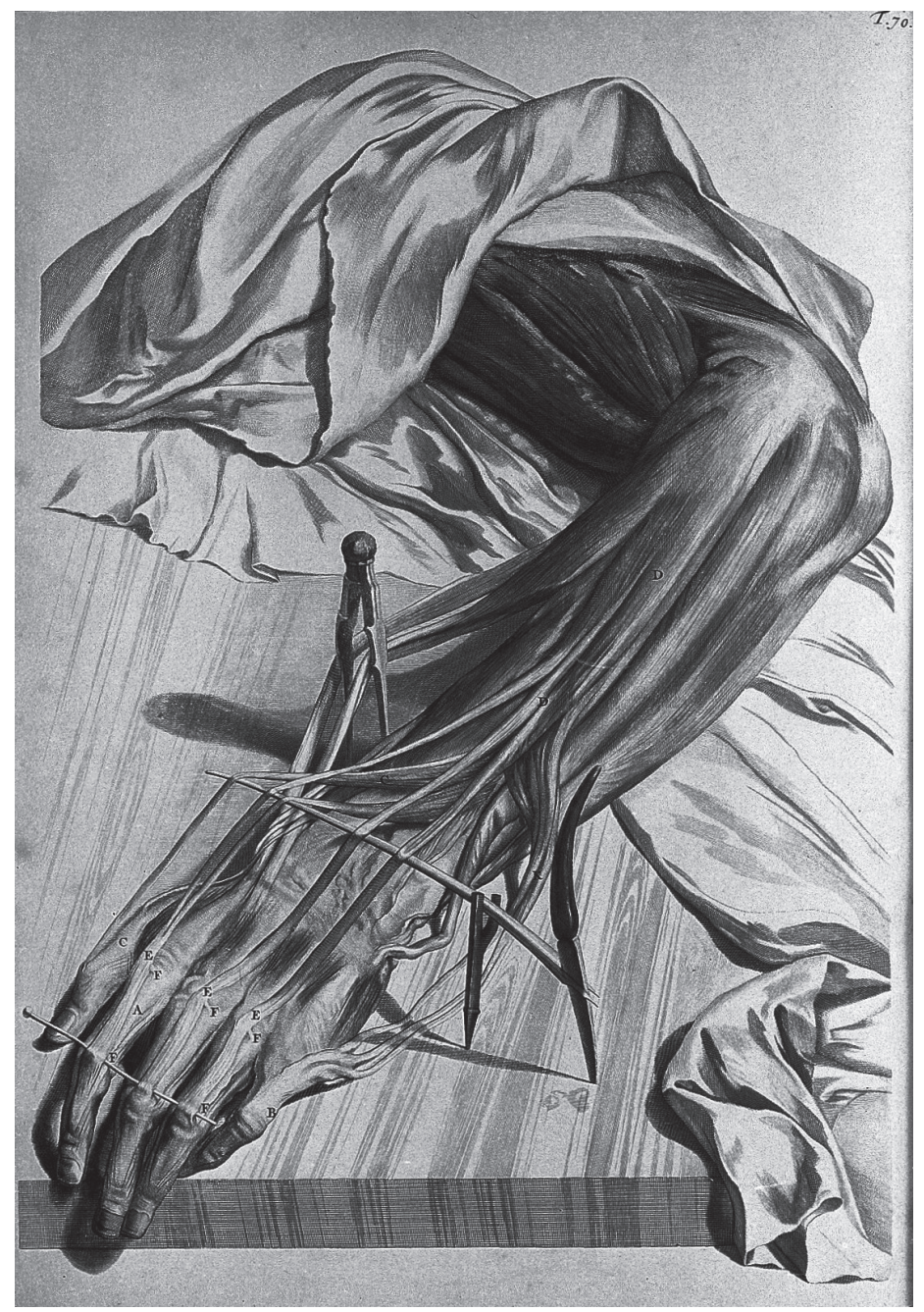

Wellcome Library, London

Fig. 4. Dissected hand and arm, from Govard Bidloo, Anatomia humani corporis: centum \& quinque tabulis, engraved by G. de Lairesse, Amsterdam 1685.

${ }^{21}$ On 'surfacing the body interior', see Taylor 2005, pp. 746-8. 
peeled away. ${ }^{22}$ This convention is respected in the adaptations of Chinese body maps published with Ten Rhijne's account of acupuncture (see figure 5), where similar flaps have been added.

Additionally, the pose of one of Ten Rhijne's 'Chinese' figures shares many features with a western anatomical image published in London only two years earlier. (See figure 2 above). Ten Rhijne himself would have been familiar with an earlier version of this same figure, which appeared in an anatomical treatise he presented to the Japanese official charged with controlling foreign trade in $1765 .{ }^{23}$ Although rendered visually more familiar to European eyes by the addition of 'dissected' flaps of skin, Ten Rhijne's versions preserved the most distinctive aspect of acupuncture maps: the jing-luo. Ten Rhijne also discussed the jing-luo in his text, though he acknowledged that 'a person especially skillful in the art of anatomy will belittle the lines and the precise points of insertion'. ${ }^{24} \mathrm{He}$ knew that a Western audience, used to the increasingly sophisticated heuristics of contemporary anatomical atlases, might have other criticisms as well, that they would 'censure the awkward presentation of the short notes on the diagrams, when these should be more closely identified with the walls of the blood vessels... ${ }^{25}$ Nonetheless, he told his readers: ' $[t]$ he various movements of the blood must be learned through the precepts and rules as layed down by the Chinese... if the cure is to be undertaken according to their regimen. ${ }^{26}$ In other words, he asserted that theory and practice were inseparable. Ten Rhijne's successor would disagree, erasing the jing-luo-fundamental to any understanding of acupuncture's modus operandi-from his own visual and textual accounts of the technique.

Engelbert Kaempfer, like Ten Rhijne, served as medical officer to the Dutch community on Deshima. Also like his predecessor, he was a close observer, deeply interested in the medicine of Japan. However, he was considerably less sympathetic to its different model of the body. Where Ten Rhijne urged his European counterparts to experiment with acupuncture as it was used in China and Japan - as a compound entity combining practice and theory via needles, maps, and body-model—Kaempfer divorced the former element from the latter. Discussing both moxibustion and acupuncture, Kaempfer described in minute detail the exact methods practised in relation to burning, needle-insertion, and subsequent needle movement. He stressed the care

\footnotetext{
22 The classic discussion of 'virtual witnessing' is Shapin and Schaffer 1985; for more on anatomical art in the West, see Carlino 1999.

${ }^{23}$ Cook 2004, pp. 25-6.

${ }^{24}$ Translated in Carrubba and Bowers 1974, p. 376.

25 Ibid.

${ }^{26}$ Ibid.
} 


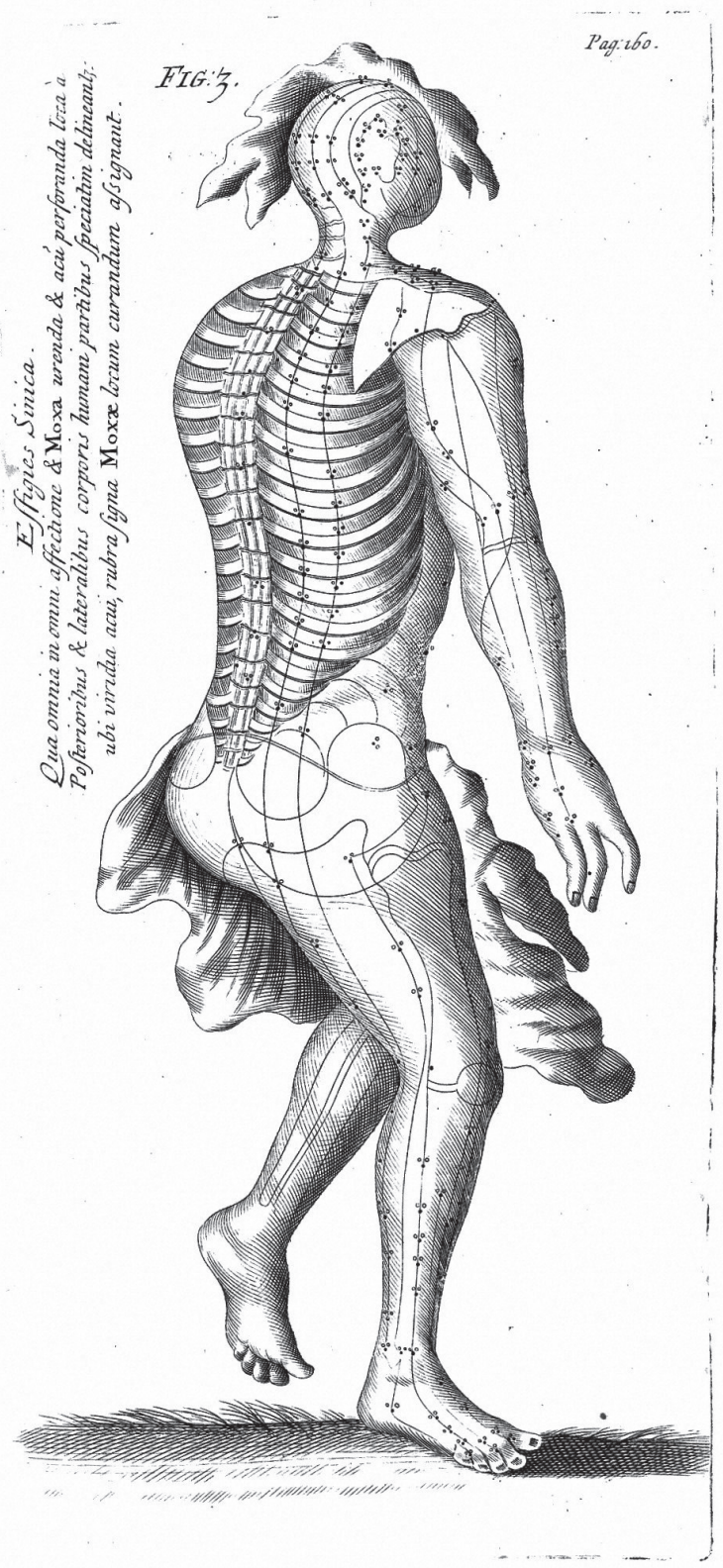

Wellcome Library, London

Fig. 5. 'Effigies Sinica' from Willem Ten Rhijne, Dissertatio de arthritide: mantissa schematica: de acupunctura London 1683. Compare to John Browne's partially dissected figure above, figure two. 
taken in choosing the site for needle insertion or the placement of moxa, but he dismissed the jing-luo altogether: they were not anatomical and therefore not 'reasonable':

The Main art lies in the knowledge of the parts which it is proper to burn [or puncture] in particular distempers.... [O]ne would reasonably imagine that place to be the most proper which is nearest to the affected part, yet the operators frequently choose such others, as are not only very remote from it, but would be found, upon an Anatomical inquiry, to have scarce any communication with it, no more than by the common integuments... the most skillful Anatomist would be at a loss to find out any particular correspondence of these remote and differing parts with one another. ${ }^{27}$

In an earlier version of his account, Kaempfer added a further comment on his Japanese counterparts: 'The results do not allow us to accuse them all of deception, yet sound reasoning does not permit us to testify in defence of all of them.' ${ }^{28}$ The images Kaempfer included reflected and emphasised his materialist bias and scepticism of Chinese understandings of the body (see figure 6). ${ }^{29}$ They carefully charted the points themselves, the empirical efficacy of which Kaempfer had witnessed. But they erased the structures underpinning them as anatomically disproven. With these images, the theoretical rationale of acupuncture's efficacy disappeared.

Images and texts addressing Chinese (and Japanese) medicine were repeatedly examined by Western audiences over the course of the eighteenth and nineteenth centuries, though not always in conjunction with each other. The results, despite their authors' best efforts, were mixed. For some, the images served to confirm what (often exoticised) translations of Chinese medical texts had already suggested: namely, that the medical skill of the East was negligible. English polemicist William Wotton, for example, wrote scathingly of Cleyer's illustrated translations: 'The anatomical figures annexed to the tracts, which also were sent out of China, are so very whimsical, that a man would almost believe the whole to be a banter, if these theories were not agreeable to the occasional hints that may be found in the travels of the missionaries. ${ }^{30}$ While Wotton included a short extract of the translated text on the grounds that 'few will in all probability have patience to go through them, since they are not very pleasant to read', he deleted the images altogether. ${ }^{31}$ On the other

${ }^{27}$ Kaempfer 1728, pp. 41-2.

28 Translated in Bowers and Carrubba 1970, pp. 270-310.

29 For an expanded treatment of these two authors and texts, see Bivins 2000, chapter 2 .

30 Wotton 1694, p. 152.

31 Wotton 1694, p. 147. 




Wellcome Library, London

Fig. 6. 'Kiusui kagami Unendorum locorum Speculum' from Englebert Kaempfer, The History of Japan, London 1728. Note the absence of jing-luo.

hand, almost a century later, Dujardin, in his compendious and influential Histoire de la Chirurgie reproduced Ten Rhijne's images exactly. ${ }^{32}$ Other scholars, including the French Encyclopédistes, mentioned the existence of maps and figures depicting acupuncture or moxibustion points, sometimes referring to Ten Rhijne, Kaempfer, or Dujardin-but did not reproduce the images themselves. Images were expensive to print, and these 'curious anatomies' were clearly not considered important enough to justify their additional cost.

Although maps of the body's surface were among the most dramatic and controversial Western representations of acupuncture, they did not provide the only images of the technique. The technology of acupuncture-needles, needle cases, striking implements and, in the nineteenth century, three-dimensional figures-were also well-studied and frequently portrayed, particularly in medical texts and instrument catalogues (see figure 7).

\footnotetext{
${ }^{32}$ Dujardin 1774, pp. $75-98$.
} 


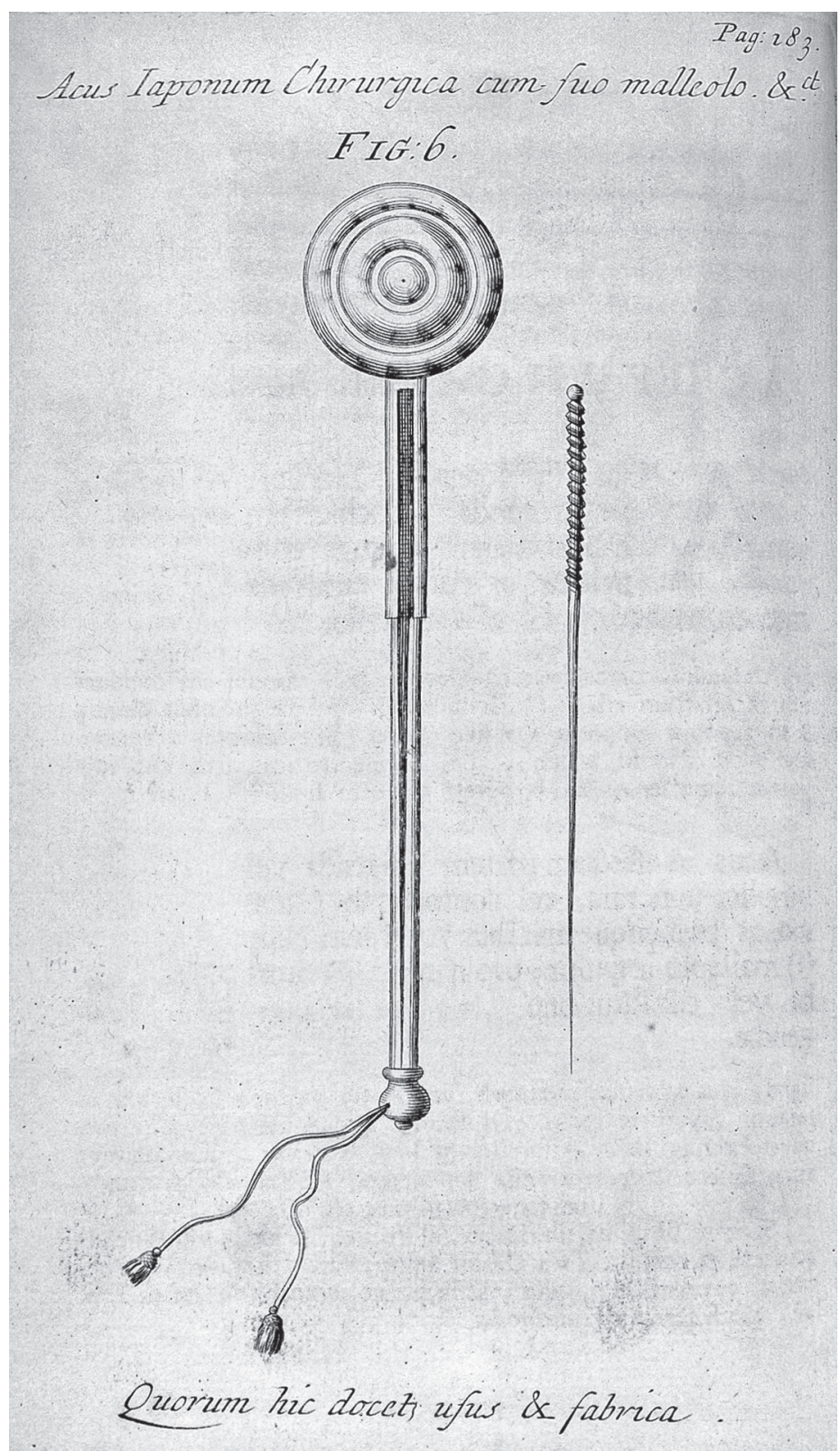

Wellcome Library, London

Fig. 7. Acupuncture implements, as illustrated in Willem Ten Rhijne, Dissertatio de arthritide: mantissa schematica: de acupunctura London 1683. 
Even authors who ignored Ten Rhijne and Kaempfer's body-maps included images of the implements of acupuncture. ${ }^{33}$ The drawback to their visual prevalence, and indeed the (again) orientalised beauty of many of these images, was that they tacitly reinforced Western perceptions of acupuncture as a standalone technology, to be applied purely empirically and in accordance with Western anatomical understandings of the body. Later, as in James Morss Churchill's influential nineteenth-century British study of the technique, the deliberate Westernisation of therapeutic needling was reflected in a very Westernised image of the needle itself (see figure 8). These images, however, were nonetheless important in widening access to the technique, much as they had been in the nearly contemporaneous case of the stethoscope. ${ }^{34}$ Doctors looking at Churchill's pictures could make their own acupuncture needles, and could test in person what he described as the miraculous, incomprehensible, and, therefore, almost unbelievable efficacy of therapeutic needling in relieving certain conditions.

The late nineteenth and early twentieth centuries brought significant changes in the pathways by which Westerners, whether of the laity or the medical profession, accessed information about acupuncture. Immigration brought whole communities - with their medical practitioners and remedies-to Western Europe and North America where the latter swiftly gained a following among locals. ${ }^{35}$ In 1887, for example, a US commentator noted: 'Many of the Chinese stores in our American cities keep a supply of Chinese drugs, and all of them sell Chinese proprietary medicines.' Alongside these over-the-counter remedies, such stores often hosted a Chinese practitioner able to diagnose and treat patients individually. ${ }^{36} \mathrm{New}$ and more accurate translations of Chinese medical, cosmological, and philosophical texts likewise became more readily available, and Chinese language originals were mass-produced for the migrants; in Philadelphia, for example, complete copies of the Qing imperial medical compendium from 1742, the Golden Mirror (Yizong jinjian), sold for $\$ 2.25$ in $1887 .{ }^{37}$ Chinese culture and its productions more generally became the subject of popular interest and enquiry, sometimes in ways that encouraged appreciation, rather than Orientalism or racial stereotyping. ${ }^{38}$ And more

\footnotetext{
33 See, for example, Heister 1743, p. 314.

34 See above, p. 5 and Smith 1998.

35 Liu 1998; Marcus and Chen 2011.

36 Culin 1887. See also Liu 1998; Shah 2001, pp. 55-6, 213 et passim.

37 For an interesting account of the creation of the Golden Mirror itself, and the ways in which this too was a process of selection, translation, and sometimes erasure, see Hanson 2003.

38 Zboray and Zboray 2004.
} 


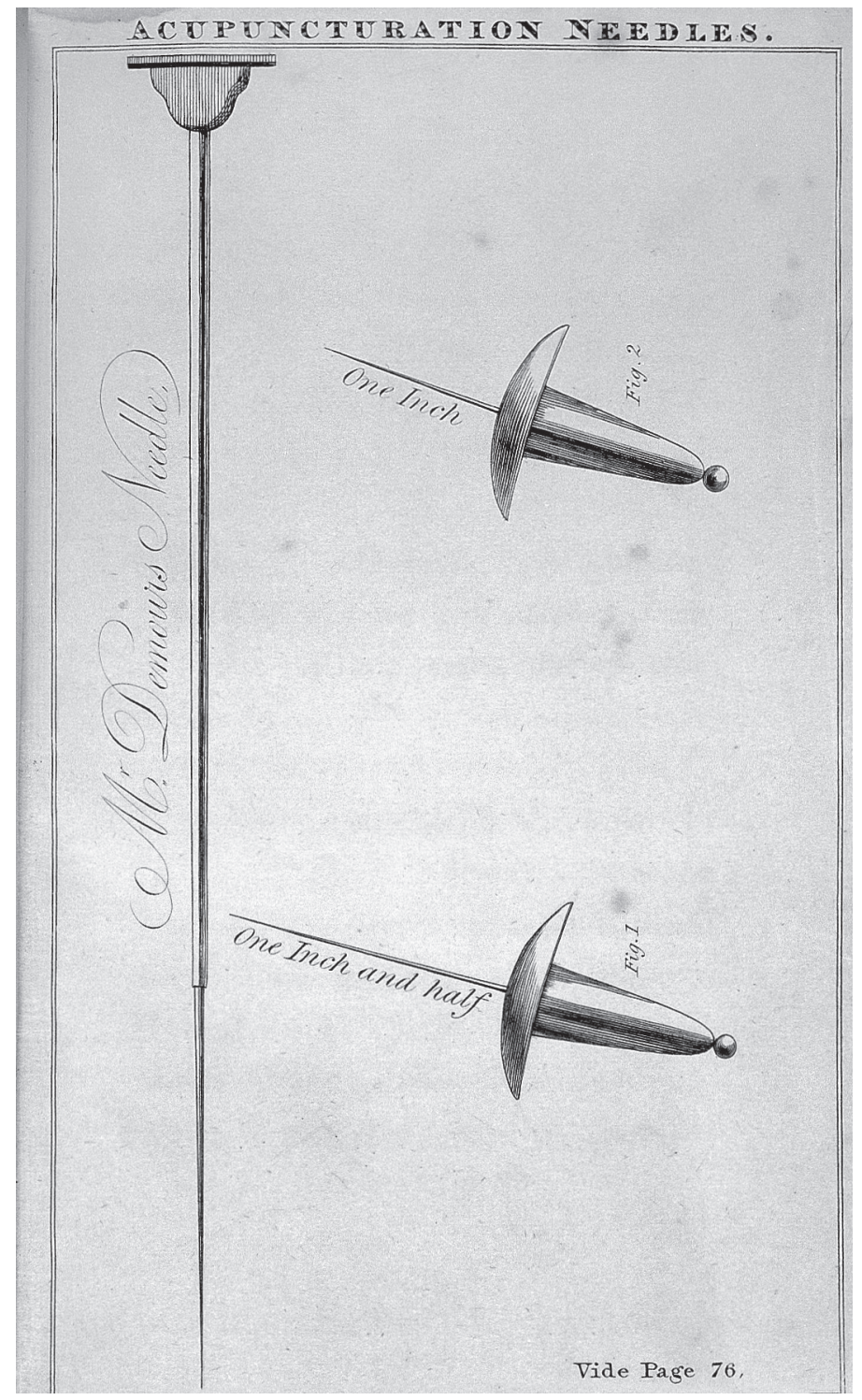

Wellcome Library, London

Fig. 8. 'Mr Demours' Needles', from James M. Churchill, A treatise on acupuncturation; being a description of a surgical operation originally peculiar to the Japonese [sic] and Chinese, and by them denominated Zin-King, now introduced into European practice, with directions for its performance, and cases illustrating its success, London, 1821. 
Westerners were able to travel to East Asia to observe or study acupuncture in situ.

Nonetheless, even with these new avenues of transmission, images have remained central to understandings of acupuncture in the West. Like their predecessors, they reflect syntheses of different models of the body. Anatomical carcasses stripped of skin but covered in xue, dominate educational texts, while popular accounts and introductions-for example, Ted Kaptchuck's Web That Has No Weaver-carry diagrams, which could have been taken directly from Ten Rhijne's 'Japanese' images of three centuries before. Western commercial representations of acupuncture, meanwhile, heavily emphasise the exotic, the unusual, and the historic qualities of 'Traditional Chinese Medicine' in images as well as text. ${ }^{39}$ Kaempfer's illustrations, in particular, remain popular. Their persistence may offer testimony to the accuracy with which he estimated Western tolerances for non-Western medical expertise-or to the ease with which their simpler lines, unlike those of Ten Rhijne's images, could be copied and reproduced. Visual distinctiveness here re-emphasises the now-attractive qualities of theoretical and practical divergence from a Western medical culture, which can be as mystifying, obscure, and alienating to its patients as Chinese medicine and culture once was to Western eyes.

So what, more broadly, do acupuncture's images, understood in their historical context, tell us about the processes by which medical knowledge and expertise become globalised? Clearly, whether philosophical, anthropological, or historical, any model of transmission of expertise must include the following processes: the observation and collection of information, specimens, and technologies (and inevitably, therefore both accidental and deliberate selection); the translation, interpretation, and description of the observed and collected materials; the publication and/or display of such materials in the destination culture; and the reception, re-interpretation, and response to them by the members of that culture. Both culture and chance inflect each stage of the process. A closed origin community, a higher market value for secret knowledge, cultural traditions about bodily privacy or sanctity, the mandates of governments, shipwreck, bookworm, sudden death, and, of course, the personal tastes, ambitions, and intellectual hobbyhorses of observers and observed: all can act as drivers of, or as limits to, comprehensive and persuasive crosscultural transmission. Images cannot evade the exigencies of selection or of translation-nor can they escape culturally specific interpretation. Indeed, as Western responses to Ten Rhijne and Kaempfer's images suggest, they may be

39 For more on twentieth-century perceptions of acupuncture, see Bivins 2002, pp. 84-105. For more on the use of tradition and exoticism in the commercial spread of Chinese (and Ayurvedic) medicine, see Bivins 2007, pp. 117-99. 
particularly susceptible to interpretive drift and redefinition. Yet, as demonstrated by their persistence in the face of rapidly shifting technologies of both pedagogy and diagnosis, images remain essential to the teaching and practice of medicine. Ten Rhijne himself acknowledged both the limitations and the value of imagery in communicating knowledge at a distance in another treatise, on leprosy in Asia:

It is not enough, for one who has never seen the disease, to send a description of it, consisting of a few hypotheses formed from guesswork rather than experience...embellished, according to present day dash custom, with much true-seeming chop-logic; making the nature and particularities of the disease like the paintings which have been made of it more from imagination than from real life. ${ }^{40}$

Such flawed and partial attempts, he acknowledged, had some merit: 'if everyone adds a line, then the picture will gradually become like nature, and after thorough observation, be at last completed'. They were, in short, better than nothing. Crucially, however, Ten Rhijne exhorted his readers not to 'stare at the manikin... always keep the living object in view.' Scholars, practitioners, and patients today continue to debate whether contemporary western images (and imaginings) of acupuncture—biomedical, popular, or scholarly—are ossified, orientalised, or 'like nature', and with what experimental or experiential tools each additional line should be drawn. I have suggested here that such questions are of more than theoretical interest. Remarkable visual representations of acupuncture played a central role in acupuncture's early westward transmission and its initial reception in Europe. But with observers captivated or repelled by these 'manikins' and largely cut off from the 'living object', acupuncture as it was originally understood, practiced, and experienced (as an entity comprised of theories, practices, and technologies) was first transfigured, and then erased from view until the mid-twentieth century. ${ }^{41}$

\section{References}

Anderson, J. 2006, 'Greenhouses and Body Suits: The Challenge to Knowledge in Early HipReplacement Surgery, 1960-1982', in C. Timmermann and J. Anderson (eds.), Devices and Designs: Medical Technologies in Historical Perspective, Basingstoke: Palgrave, 175-92.

Berkowitz, C. 2011, 'The Beauty of Anatomy: Visual Displays and Surgical Education in Early Nineteenth-Century London', Bulletin of the History of Medicine, 85: 248-78.

Bivins, R. 2000, Acupuncture, Expertise and Cross-cultural Medicine, Basingstoke: Palgrave.

\footnotetext{
40 Ten Rhijne 1687 , pp. 37-40.

41 For a detailed account of this process, see Bivins 2000.
} 
2002, 'Acupuncture and Innovation: "New Age" Medicine in the NHS', in J. Stanton (ed.), Innovations in Health and Medicine, London: Routledge, 84-105.

. 2007, Alternative Medicine? A History, Oxford: Oxford University Press.

Bowers, J. and R. Carrubba 1970, 'The Doctoral Thesis of Engelbert Kaempfer: "On Tropical Diseases, Oriental Medicine and Exotic Natural Phenomenon"', Journal of the History of Medicine and Allied Sciences, 25: 270-310.

Carlino, A. 1999, Books of the Body: Anatomical Ritual and Renaissance Learning, Chicago: University of Chicago Press.

Carrubba, R. and J. Bowers 1974, 'The Western World's First Detailed Treatise on Acupuncture: Willem ten Rhijne's De Acupunctura', Journal of the History of Medicine and Allied Sciences, 29: 371-98.

Cook, H. 2004, 'Medical Communication in the First Global Age: Willem ten Rhijne in Japan, 1674-1676', Academia Sinica, 11: 16-36.

Culin, S. 1887, 'The Practice of Medicine by the Chinese in America', reprinted from Medical and Surgical Reporter, $19 \mathrm{March}$, accessible online at http://babel.hathitrust.org/cgi/pt?id=uc2. ark\%3A\%2F13960\%2Ft22b8w48v;page=root;view=image;size=100; seq=6; num=2.

Dujardin, M. F. 1774, Histoire de la Chirurgie, depuis son origine jusqu’à nos jours. Tome Premier, Paris: L'Imprimerie Royal, 75-98.

Gilman, S. 1995, Picturing Health and Illness: Images of Identity and Difference, Baltimore: Johns Hopkins University Press.

Hanson, M. 2003, 'The Golden Mirror in the Imperial Court of the Qianlong Emperor, 17391742', Early Science and Medicine, 8: 111-47.

Heister, L. 1743, A General System of Surgery in Three Parts, London: W. Innys.

Hsu, E. 1999, The Transmission of Chinese Medicine, Cambridge: Cambridge University Press.

Jenner, M. 2010, 'Tasting Lichfield, Touching China: Sir John Floyer's Senses', The Historical Journal, 53: 647-70.

Jordanova, L. 2012, The Look of the Past: Visual and Material Evidence in Historical Practice, Cambridge: Cambridge University Press.

Kaempfer, E. 1728, The History of Japan, London.

Kemp, M. 1993, “The Mark of Truth”: Looking and Learning in Some Anatomical Illustrations from the Renaissance and Eighteenth Century', in W. F. Bynum and R. Porter (eds.), Medicine and the Five Senses, Cambridge: Cambridge University Press, 85-121.

- 1996, 'Temples of the Body and Temples of the Cosmos: Vision and Visualisation in the Vesalian and Copernican Revolutions', in B. Baigrie, Picturing Knowledge: Historical and Philosophical Problems Concerning the Use of Art in Science, Toronto: University of Toronto Press, 40-85.

Kusukawa, S. and I. Maclean (eds.) 2006, Transmitting Knowledge: Words, Images and Instruments in Early Modern Europe, Oxford: Oxford University Press.

Liu, H. 1998, 'The Resilience of Ethnic Culture: Chinese Herbalists in the American Medical Profession', Journal of Asian American Studies, 1: 173-91.

Luthy, C. 2006, 'Where Logical Necessity Becomes Visual Persuasion: Decartes' Clear and Distinct Illustrations', in S. Kusukawa and I. Maclean (eds.), Transmitting Knowledge: Words, Images and Instruments in Early Modern Europe, Oxford: Oxford University Press, 97-133.

Marcus, K. and Y. Chen 2011, 'Inside and Outside Chinatown: Chinese Elites in Exclusion Era California', Pacific Historical Review, 80: 369-400.

Nicholson, M. 1993, 'The Introduction of Percussion and Stethoscopy to Nineteenth-Century Edinburgh', in W. F. Bynum and R. Porter (eds.), Medicine and the Five Senses, Cambridge: Cambridge University Press, 134-53.

Pickstone, J. 2006, 'Bones in Lancashire: Towards Long-Term Contextual Analysis of Medical Technology', in C. Timmermann and J. Anderson (eds.), Devices and Designs: Medical Technologies in Historical Perspective, Basingstoke: Palgrave, 17-36. 
Ragep, F. J. and S. P. Ragep, with S. Livesey (eds.) 1996, Tradition, Transmission, Transformation: Proceedings of two conferences on pre-modern science, held at the University of Oklahoma, Leiden: Brill.

Reiser, S. J. 1978, Medicine and the Reign of Technology, Cambridge: Cambridge University Press.

Ruse, M. 1996, 'Are Pictures Really Necessary? The Case of Sewall Wright's "Adaptive Landscapes"', in B. Baigrie, Picturing Knowledge: Historical and Philosophical Problems Concerning the Use of Art in Science, Toronto: University of Toronto Press, 303-38.

Scheid, V. 2002, Chinese Medicine in Contemporary China: Plurality and Synthesis, Durham, N.C.: Duke University Press.

Schiebinger, L. 1989, The Mind Has No Sex: Women in the Origins of Modern Science, Cambridge MA: Harvard University Press.

Scholar, R. 2006, 'Introduction', in S. Kusukawa and I. Maclean (eds.), Transmitting Knowledge: Words, Images and Instruments in Early Modern Europe, Oxford: Oxford University Press, $1-9$.

Shah, N. 2001, Contagious Divides: Epidemics and Race in San Francisco's Chinatown, Berkeley: University of California Press.

Shapin, S. and S. Schaffer 1985, Leviathan and the Air-Pump: Hobbes, Boyle, and the Experimental Life, Princeton: Princeton University Press.

Smith, H. 1998, 'The Transmission of Medical Knowledge: The Introduction and Acceptance of Mediate Auscultation in Great Britain, 1816-1843', unpublished doctoral dissertation, University of Minnesota.

Taylor, J. 2005, 'Surfacing the Body Interior', Annual Review of Anthropology, 34: 741-56.

Ten Rhijne, W. 1687, Treatise on the Asiatic Leprosy, Amsterdam: Abraham Van Someren: 37-40, trans. D. Schoute in Opuscula Selecta Neerlandicorum De Arte Medicale Fasc. 14, Amstelodami: 'Sumptibus Societatis', 1937.

Timmermann, C. and J. Anderson (eds.) 2006, Devices and Designs: Medical Technologies in Historical Perspective, Basingstoke: Palgrave.

Wotton, W. B. D. 1694, Reflections upon Ancient and Modern Learning, London: Peter Buck.

Zboray, R. and M. S. Zboray 2004, 'Between "Crockery-dom and Barnum": Boston's Chinese Museum, 1845-47’, American Quarterly, 56: 271-307. 